\title{
Mechanical Property Research for Recycled Concrete Injected with Self-Compacting Mortar
}

\author{
Guo-Chen SANG ${ }^{a}$, Li CUI ${ }^{b,}$, Xiao-Gen TONG ${ }^{c}$, Yi-Yun ZHU ${ }^{d}$, Qin ZHAO
}

(School of Civil Engineering and Architecture, Xi'an University of Technology, Xi' an 710048,China)

asangguochen@xaut.edu.cn, ${ }^{\mathrm{b}}$ cuili4488@163.com, ${ }^{\mathrm{c}} 13484513498 @ 163 . c o m$

,'zyyun@xaut.edu.cn, ${ }^{\mathrm{e}}$ zhaoqin8866@xaut.edu.cn

*Corresponding author: cuili4488@163.com

Keywords: Recycled concrete, Self-compacting mortar, Aggregate property, Compressive strength

\begin{abstract}
Due to the poor workability of recycled concrete caused by heavy water absorption, coarse surface and multiple spaces of recycled coarse aggregate, it is proposed that pre-allocated self-compacting mortar shall be adopted to prepare recycled concrete, which solves such problems arising from poor workability of concrete. The recycled concrete (hereinafter referred to as RC) prepared by this method are provided with such properties as rapid hardening and early strength. Its compressive strength can reach above $20 \mathrm{MPa}$ for $2 \mathrm{~h}$ and above $40 \mathrm{MPa}$ for $28 \mathrm{~d}$. Researches show that when actual Water-Dry mix mortar ratio is 0.18 , the compressive strength development trend of recycled concrete is consistent with that of self-compacting mortar. But the strength development of natural concrete (hereinafter referred to as NC) is delayed to certain degree, compared with that of self-compacting mortar. When actual water-Dry mix mortar ratio is 0.20 and 0.22 , the early strength of concrete is higher than that of self-compacting mortar, while its later strength is lower than self-compacting mortar. RC compressive strength is lower 4\%-15\% than NC approximately, but it may be higher $0.56 \%-8.5 \%$ than $\mathrm{RC}$ without regard to the added water consumption of recycled coarse aggregate.
\end{abstract}

\section{Foreword}

In recent years, with the increased of the awareness on environmental protection, the research on environment-friendly building materials is also increasing. Concrete in building materials accounted for the main part, so some new energy-saving building materials have emerged, such as translucent light concrete, foam concrete, recycled concrete, etc. These new materials can make the building more greener and environmental protection. Recycled aggregate concrete refers to new concrete, which is prepared via recycled aggregate (processed via crushing abandoned concrete) partially or completely replacing natural aggregate, hereinafter referred to as recycled concrete (RC). Mass ive abandoned concrete are generated every year due to the removal of old buildings. Recycled concretes ensure that the circulation and high-efficient utilization and green and environmental protection of concrete materials are realized during removal[1]. At present, recycled concrete technology is not sound and at experimental study stage. There is no current standard applicable to it. Thus, its application in practical engineering is very limited. The main reason why technical study of recycled concrete is much and application is less is that the property of recycled aggregate is obviously different with that of natural aggregate. Due to the different source of recycled aggregate, the different properties of its primary concrete may result in large discreteness of recycled concrete in mechanical property. Therefore, the preparation and property regulation of recycled concrete is far different than normal concrete. Relatively extensive internal defects and large porosities of recycled coarse aggregate cause its low intensity and large water absorption[2], which results in poor working performance of recycled concrete mixture. And it is inconvenient for construction.

This test adopts previously-prepared self-compacting mortar to prepare recycled concrete. High-fluidity of self-compacting mortar ensure it to fill all the spaces without external force and its microdilatancy property after condensation and hardening guarantee that mortar and recycled coarse 
aggregate are firmly bonded, which effectively solves a series of problems such as poor fluidity arising from large porosity and intensive water absorption of recycled aggregate, and low later strength arising from indirectly enlarged water-cement ratio.

\section{Test Part}

\subsection{Raw Materials for Test}

Self-compacting dry mash: self-compacting dry mash made by the laboratory with maximum particle size of $2.5 \mathrm{~mm}$.

Aggregate: Natural aggregates are referred as NA. The recycled aggregates made of laboratory-abandoned concrete test blocks are referred as RA. Sieve coarse aggregates to ensure that particle size range is $5.0-31.5 \mathrm{~mm}$. The basic properties of coarse aggregates are detailed in Table 1.

Water: refers to tap water in laboratories.

Table 1 Basic Properties of Coarse Aggregate

\begin{tabular}{lllll}
\hline Type of aggregate & $\begin{array}{l}\text { Particle diameter } \\
(\mathrm{mm})\end{array}$ & $\begin{array}{l}\text { Crush index } \\
(\%)\end{array}$ & $\begin{array}{l}\text { Water content } \\
(\%)\end{array}$ & Water absorption (\%) \\
\hline NA & $5 \sim 31.5$ & 9.00 & 0.08 & 0.31 \\
RA & $5 \sim 31.5$ & 17.09 & 0.65 & 4.50 \\
\hline
\end{tabular}

\subsection{Test Design}

Previously prepared dry mix mortar shall be adopted for the test and shall be stirred and made into self-compacting mortar with water when application. Three different water-Dry mix mortar ratios $0.18,0.20$ and 0.22 shall be adopted. Pour weighing dry mix mortar and mixing water into mortar mixer and stir it evenly for $3 \mathrm{~min}$ and self-compacting mortar come into being. The self-compacting mortar fluidities under different water-dry mix mortar ratio determined according to the china standard [3] are detailed in Table 2. The fluidity of self-compacting mortar is $320 \mathrm{~mm}$ $-440 \mathrm{~mm}$ and its flow property totally meet the test requirements.

Table 2 Properties of Self-compacting Mortar

\begin{tabular}{cll}
\hline \multirow{2}{*}{ Water-Dry mix mortar ratio } & \multicolumn{3}{c}{ Fluidity $(\mathrm{mm})$} \\
\cline { 2 - 3 } & Initial & $15 \mathrm{~min}$ \\
\hline 0.18 & 325 & 340 \\
0.20 & 410 & 430 \\
0.22 & 435 & 428 \\
\hline
\end{tabular}

Two different types of coarse aggregate NA and RA are adopted in the test with fixed ratio. Specimen preparation is conducted according to the mixture ratio in Table 3. NC-, RC- test series are completed and serial number 1,2 and 3 represent respectively actual water-dry mix mortar ratio $0.18,0.20$ and 0.22 . Since recycled coarse aggregates are subject to larger exogenic action during shattering process, massive microcracks will appear in its interior and cement mortar may be attached to its surface, all of which will cause larger porosity and high water absorption. Its water scarcity amount is the difference between water contents in the state of nature and under the condition of saturated surface dry. And its additional water consumption is relevant to the water scarcity amount[4]. The water absorption of recycled aggre gate can reach $85 \%$ of saturation level in $10 \mathrm{~min}$ and $95 \%$ in $30 \mathrm{~min}$ [5]. Additional water consumption is not the product of water absorption and consumption of recycled aggregate, for the condition of recycled aggregate is different with that in the water and cannot reach the saturation when it is mixed with each material. Therefore, the 
actual water-cement ratio is calculated via water consumption conversion coefficient [6] in this research. Actual water-cement ratio is the water cement ratio corresponding to actual water consumption of recycled concrete and is calculated according to the following Eq. 1 [7]:

$$
\frac{w}{c}=\frac{m_{w}-k m_{g}\left[\left(w_{R A}-v_{R A}\right)-\left(w_{N A}-v_{N A}\right)\right]}{m_{c}}
$$

Where,

$m_{c}$ - the mass of concrete;

$m_{w}-$ the total water consumption of recycled concrete;

$k$ - the water consumption conversion coefficient, adopting $0.5[6]$;

$m_{g}$ - the consumption of recycled coarse aggre gate;

$v_{R A}$ - the water content of recycled coarse aggregate;

$w_{R A}$ - the water absorption of recycled coarse aggregate;

$v_{N A}$ - the water content of natural coarse aggregate;

$w_{N A}$ - the water absorption of natural coarse aggregate.

It is known from the Eq. 1 that when water-dry mix mortar ratios of self-compacting mortar are $0.18,0.20$ and 0.22 , the water-cement ratio of prepared natural aggregate concrete is $0.36,0.40$ and 0.44 respectively. When water-dry mix mortar ratios of self-compacting mortar are $0.20,0.22$ and 0.24 , the nominal water-cement ratio of prepared recycled aggregate concrete are $0.40,0.44$ and 0.48 respectively, but its actual ratio is $0.36,0.40$ and 0.44 . Thus, NC and RC are provided with the same actual water-cement ratios.

Table 3 Concrete Mixture Ratio

\begin{tabular}{cccccc}
\hline \multirow{2}{*}{$\begin{array}{c}\text { Specimen Water-dry mix } \\
\text { No. }\end{array}$} & mortar ratio & & $\begin{array}{c}\text { Self-compacting } \\
\text { mortar }\end{array}$ & \multicolumn{2}{c}{ Coarse aggregate } \\
\cline { 5 - 6 } NC1 & 0.18 & 540 & 3000 & Natural aggregate & Recycled aggregate \\
NC2 & 0.20 & 600 & 3000 & 3600 & - \\
NC3 & 0.22 & 660 & 3000 & 3600 & - \\
RC1 & 0.20 & 600 & 3000 & 3600 & - \\
RC2 & 0.22 & 660 & 3000 & - & 3600 \\
RC3 & 0.24 & 720 & 3000 & - & 3600 \\
\hline
\end{tabular}

\subsection{Test Methods}

(1)For performance test of self-compacting mortar, put dry mix mortar and water into mortar mixer, stir at uniform speed for $3 \mathrm{~min}$, pour to the mould and adopt $40 \mathrm{~mm} \times 40 \mathrm{~mm} \times 160 \mathrm{~mm}$ of specimen. Remove the mould after $2 \mathrm{~h}$ and maintain under standard condition, and measure its flexural strength and compression strength at $2 \mathrm{~h}, 4 \mathrm{~h}, 1 \mathrm{~d}$ and $28 \mathrm{~d}$. Test methods according to the china standard[8]. Experimental apparatuses are DKZ-5000 type electric bending machine and WAW-1000 microcomputer control electro-hydraulic servo universal testing machine.

(2)Previously put coarse aggregate into the mould at the height of half of the mould once. Pour prepared self-compacting mortar to coarse aggregate in template evenly and vibrate it simultaneously until the aggregate spaces are fully filled with mortar and mortar is returned to the surface of aggregate. Place the residual coarse aggregate and repeat the above operation. Maintain the prepared concrete specimens under standard maintenance conditions. Remove the mould of specimens after $2 \mathrm{~h}$ and measure its compressive strength at $2 \mathrm{~h}, 4 \mathrm{~h}, 1 \mathrm{~d}$ and $28 \mathrm{~d}$. $100 \mathrm{~mm} \times 100 \mathrm{~mm} \times 100 \mathrm{~mm}$ of specimens shall be adopted for the test; 3 blocks of specimens are for 
each group. The determination of concrete compressive strength shall be strict accordance with Standard for china[9].

\section{Test Results and Analyses}

\section{1the Effect of Water-Dry Mix Mortar Ratio on Concrete Mechanics Property}

The test results show that the compressive strengths of $\mathrm{NC}$ and RC reduce gradually with the increase of nominal water-dry mix mortar ratio. It is known that when NC water-dry mix mortar ratio is enlarged from 0.18 to 0.22 , its compressive strength will reduce by $14.49 \%$ for $2 \mathrm{~h}, 22.59 \%$ for $4 \mathrm{~h}$ and $28.33 \%$ for $28 \mathrm{~d}$ from Fig.1(a). Fig.1(b) indicates that when RC water-dry mix mortar ratio is enlarged from 0.20 to 0.24 , its compressive strength will reduce by $9.38 \%$ for $2 \mathrm{~h}, 12.98 \%$ for $4 \mathrm{~h}$ and $27.36 \%$ for $28 \mathrm{~d}$. It is observed that if water- material ratio increase, concrete compressive strength will decrease and the effect of water-dry mix mortar ratio on compressive strength increases with the growth of age.

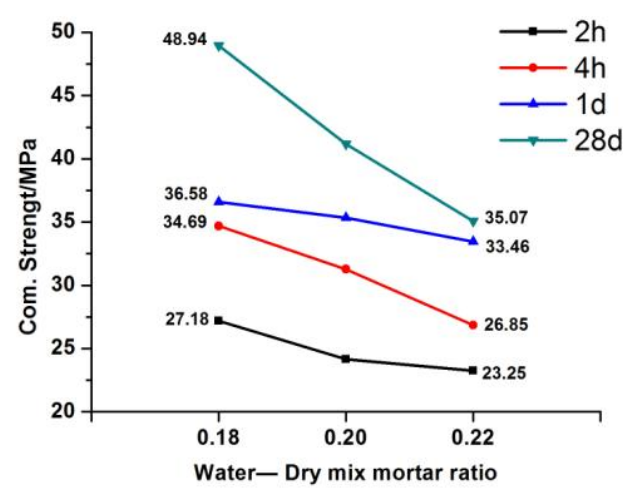

(a)

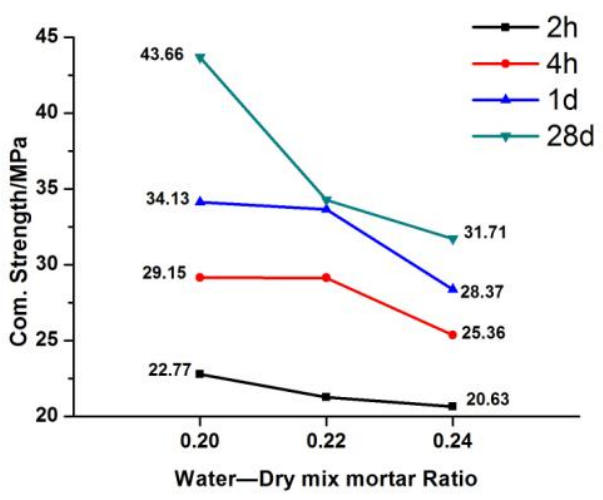

(b)

Fig.1 Effect of water-dry mix mortar ratio on compressive strength

$$
\text { (a: natural aggregate concrete } \quad b \text { : recycled concrete) }
$$

\subsection{The Relationship between Self-Compacting Mortar Strength and Concrete Strength}

Figure 2 shows that the strength of self-compacting mortar and concrete under the water-dry mix mortar ratio, the strength of self-compacting mortar and concrete were used the $2 \mathrm{~h}, 4 \mathrm{~h}, 1 \mathrm{~d}, 28 \mathrm{~d}$ strength and then make a contrast to reveal the relationship of the strength between them. As shown in Fig.2, concrete compressive strength and self-compacting mortar compressive strength of two different types of aggregates under nominal water-dry mix mortar ratio increase with the growth of age. As shown in Fig.2 (a), when the water-dry mix mortar ratio of self-compacting mortar is 0.18 , the strength growth trends of RC and self-compacting mortar are similar in 28d, while the growth trend of NC compressive strength becomes slow from $4 \mathrm{~h}$ to $1 \mathrm{~d}$. It is shown that the compression strength value of self-compacting mortar is always greater than that of $\mathrm{NC}$, and $\mathrm{NC}$ is greater than $\mathrm{RC}$. It is indicated that when water-dry mix mortar ratio is 0.18 , the compressive strength growth trend of recycled concrete is consistent with that of self-compacting mortar. But the strength development of natural concrete is delayed to certain degree, compared with that of self-compacting mortar. Owing to the large porosity and strong water absorbing capacity of recycled aggregate in recycled concrete, a "inner maintenance" is formed when the mixing water absorbed in the mixture of recycled aggre gate starts to release and be used for hydration reaction of self-compacting mortar. Therefore, its strength can maintain rapid growth.

As shown in Fig.2(b), when the water-dry mix mortar ratio of self-compacting mortar is 0.20 , the strength growth trends of $\mathrm{RC}$ and $\mathrm{NC}$ are similar at 1d, while the growth of RC compressive strength becomes slow after 1d.The compressive strength of self-compacting mortar at $2 \mathrm{~h}$ is lower 
than $\mathrm{NC}$, but greater than RC. And at $4 \mathrm{~h}$ the compressive strength of self-compacting mortar is lower than $\mathrm{RC}$, and $\mathrm{RC}$ compressive strength is lower than NC. Then it is always greater than RC and NC for the later age. It is indicated that when the water-dry mix mortar ratio is 0.20 , the effect of self-compacting mortar on early concrete strength reduces and that of aggregate strength on early concrete strength enlarges.

As shown in Fig.2(c), when the water-dry mix mortar ratio of self-compacting mortar is 0.22 , its compressive strength at $2 \mathrm{~h}$ and $4 \mathrm{~h}$ is lower than $\mathrm{RC}$ and $\mathrm{RC}$ compressive strength is lower than NC. Then the compressive strength of self-compacting mortar is always greater than RC and NC. Early concrete strength is higher than self-compacting mortar, while later strength is lower, which shows that the influence factor for early concrete strength is aggregate strength. Since aggregate strength at early stage is greater than self-compacting mortar strength, concrete strength is higher than self-compacting mortar, while the aggregate strength at later stage is lower, thus the concrete compressive strength is lower than the strength of self-compacting mortar.

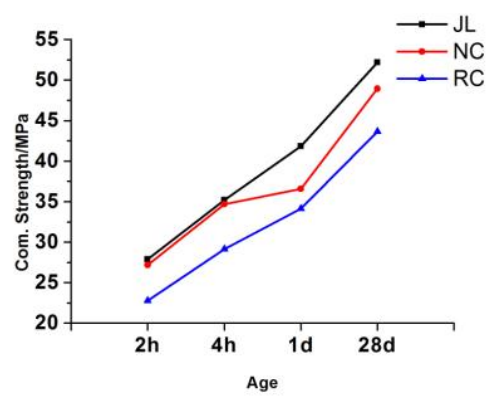

(a)

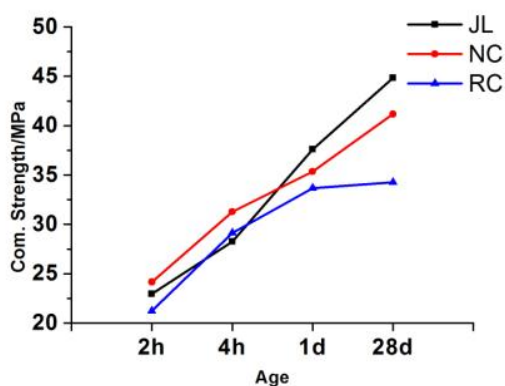

(b)

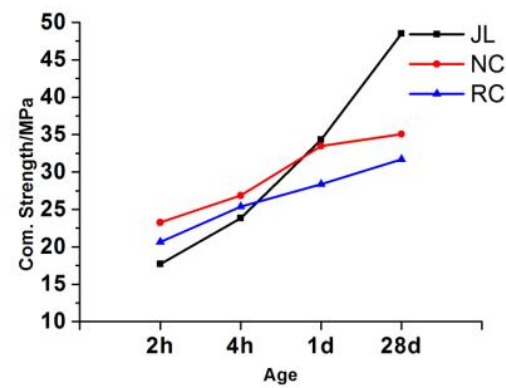

(c)

Fig.2 self-compacting mortar strength and concrete strength under different nominal water-dry mix mortar ratio

(a: water-dry mix mortar ratio is 0.18 ; b: water-dry mix mortar ratio is 0.20 ; $\mathrm{c}$ : water-dry mix mortar ratio is 0.22 )

\subsection{The Effect of Aggregate Types on Concrete Mechanics Prope rty}

Due to the mechanical crushing method in the preparation of coarse aggregate, microcrack or initial damage can be generated in its internal interface or in the interior of old mortar, which cause relatively extensive internal defects, larger porosity, low strength and larger water absorption of recycled coarse aggregate.

Fig.2 shows that the recycled aggregate additional water consumption is considered, its compressive strength is lower than $\mathrm{NC}$ and $4 \%-15 \%$ lower than normal concrete. If additional water consumption of recycled coarse aggregate is considered, only nominal water-dry mix mortar ratio shall be adopted to compare NC and RC, as shown in Fig.3. When nominal water-dry mix mortar ratio is 0.20 , it is discovered that $\mathrm{NC}$ compressive strength is $5.76 \%, 6.81 \%$ and $3.43 \%$ higher than $\mathrm{RC}$ at the age of $2 \mathrm{~h}, 4 \mathrm{~h}$ and $1 \mathrm{~d}$. But $6.05 \%$ lower than $\mathrm{RC}$ at $28 \mathrm{~d}$. When nominal water-dry mix mortar ratio is 0.22 , the compressive strength of normal concrete is $8.62 \%$ higher than $\mathrm{RC}$ at $2 \mathrm{~h}$, but lower at $4 \mathrm{~h}, 1 \mathrm{~d}$ and $28 \mathrm{~d}$. 


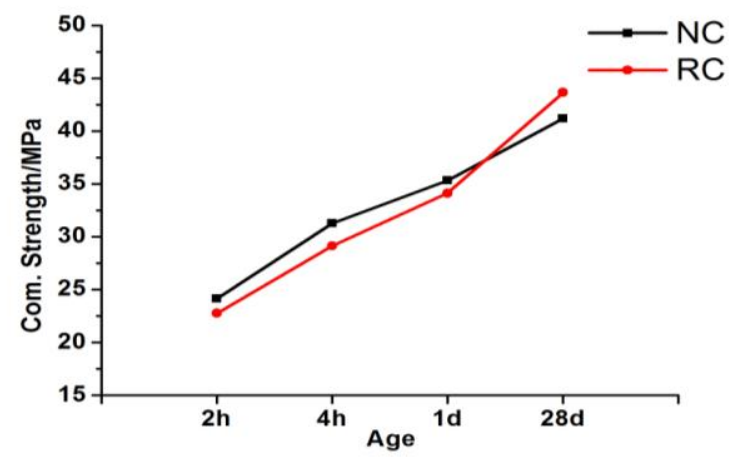

(a)

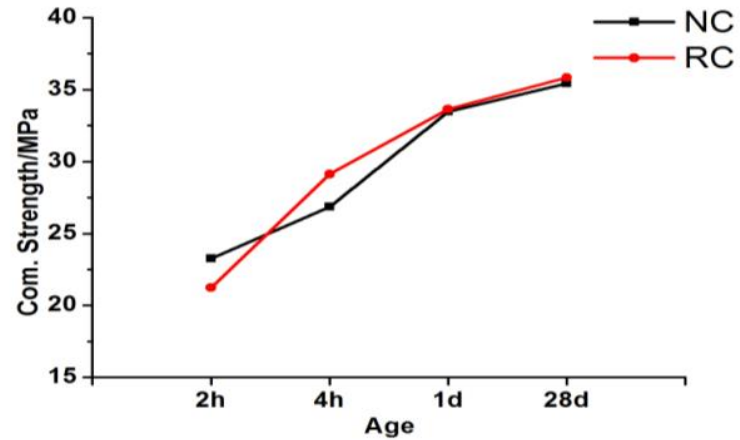

(b)

Fig. 3 concrete strength at actual water-dry mix mortar ratio

(a: water-material ratio is $0.20 \mathrm{~b}$ : water-material ratio is 0.22 )

If additional water consumption of recycled coarse aggregate is considered, its compressive strength is lower than natural aggregate concrete; if not, its early strength is lower than natural aggregate concrete, while the later strength is higher. On the one hand, compared with natural aggregate, the properties of recycled coarse aggregate is relatively poor; on the other hand, when additional water consumption is considered, the water-cement ratio of recycled concrete is indirectly enlarged so that the recycled concrete strength is reduced. When additional water consumption of recycled coarse aggregate is not considered, the reason why recycled concrete strength is lower than natural aggregate concrete strength is that the lager factor affecting early concrete strength is the properties of coarse aggregate, while the later strength higher than natural aggregate concrete is attributed to large water absorption of recycled coarse aggregate, which indirectly reduces the water-dry mix mortar ratio of concrete. And it is possible that the higher water absorption of recycled coarse aggregate make the water-dry mix mortar ratio of new mortar smaller and bonding strength stronger within the local scale of interface transition area.

Fig.4 recycled concrete SEM photo shows that the hydration products are filled with the gaps, cement mortars in self-compacting mortar penetrate cracks and holes of recycled coarse aggregate, which improves the properties of recycled coarse aggregate, and treated recycled coarse aggregate similar to chemical grouts may enhance the strength of recycled concrete[10,11,12,13,14,15].

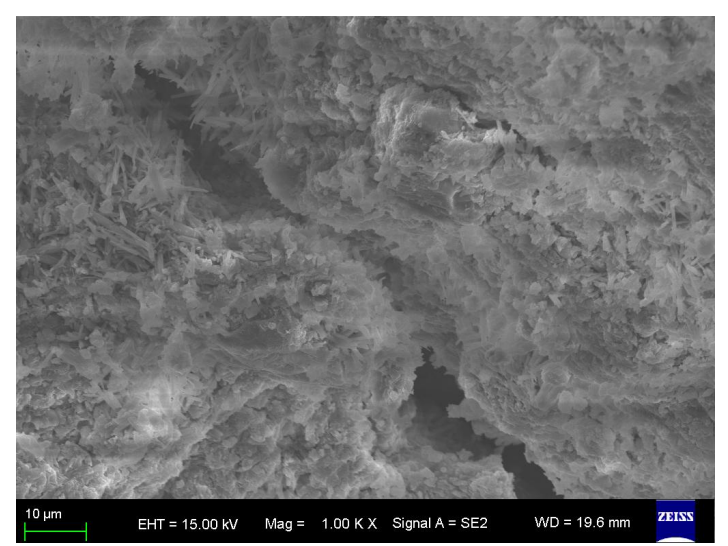

Fig.4 SEM image of recycled concrete

\section{Conclusions}

(1)Water-dry mix mortar ratio has an significant effect on concrete compression strength. With the increase of water-dry mix mortar ratio, compressive strength of concrete gradually decrease and with the growth of age, the influence of water-dry mix mortar ratio on compressive strength increasingly enlarge. 
(2)When practical water-dry mix mortar ratio is 0.18 , the compressive strength growth trend of recycled concrete is consistent with that of self-compacting smortar. But the strength development of natural concrete is delayed to certain degree, compared with that of self-compacting mortar. When water-dry mix mortar ratio is 0.22 , early concrete strength is higher than self-compacting mortar, while later strength is lower.

(3)If additional water consumption of recycled coarse aggregate is considered, compressive strength of recycled concrete is approximately $4 \%-15 \%$ lower than that of normal concrete under the same water-dry mix mortar ratio. If not, it is possible that RC compressive strength is $0.56 \%-8.5 \%$ higer than NC.

\section{Acknowledgements}

This work was supported by the National Natural Science Foundation of China (51278419);Key Social Development Program of Shanxi Province (2012K12-04-01).

\section{References}

[1]VALERIA C. Mechanical and elastic behavior of concretes made of recycled concrete coarse aggregates [J]. Construction and Building Materials, 2010, 24(9): 1616-1620.

[2]XIAO Jian-zhuang. Recycled concrete[M]. Beijing: China Building Industry Press, 2008. (in Chinese)

[3]Test Method for Fluidity of Cement Mortar (GB/T2419-2005).(in Chinese)

[4]ZHANG Xue-bing, DENG Shou-chang. Experimental research on unit water use in recycled concrete[J].CONCRETE,2004(10). (in Chinese)

[5]ZHANG Xue-bing. Compressive strength of recycled concrete mix and experimental research[D]. Xiangtan: Xiangtan University, 2005.(in Chinese)

[6]LI Kun. Recycled aggregate and recycled aggregate concrete performance[D]. Dalian: Dalian University of Technology, 2005.(in Chinese)

[7]ZHANG Yong-juan,HE Shun, ZHANG Xiong,et al. Modification of the Bolomey Formula in Recycled Aggre gate Concrete[J]. Journal of Building Materials,2012(4).(in Chinese)

[8]Method of Testing Cements-Determination of Strength (GB/T17671-1999).(in Chinese)

[9]Test Method of Mechanical Properties on Ordinary Concrete (GB/T50081-2002).(in Chinese)

[10] ZHANG Xue-bing, FANG Zhi, GUO Xue-yi, et al. Strength and failure mechanism analysis of recycled aggre gate concrete improved by DSP grout[J]. Industrial Construction, 2012,

42(4): 15-20. (in Chinese)

[11] DU Ting, LI Hui-qiang. Mechanical properties of intensified recycled aggregate concrete[J]. China Concrete and Cement Products, 2003(2): 19-20. (in Chinese)

[12]T.Matschei, B.Lothenbach, F.P.Glasser. The role of calcium carbonate in cement hydration[J]. Cement and Concrete Research,2007,37(4):551-558.

[13]Francisco J, De Casoy Basalo, Fabio Matta, et al. Fiber reinforced cement-based composite system for concrete confinement[J].Construction and Building Materials, 2011(31):1-11.

[14]ZHANG Xue-bing, WANG Gan-qiang, FANG Zhi, et al. Effect of Mixing Amount of Aggregate Intensified by RPC on the Strength of Recycled Concrete[J].Journal of Building Materials,2015(3). (in Chinese) 